\title{
INCREASING MOTIVATION FOR IN-CLASS READING COMPREHENSION IN A BUSINESS ENGLISH COURSE AT THE UNIVERSITY OF COSTA RICA(UCR)
}

\begin{abstract}
When teaching an integrated-skills English class, teachers normally know what to do to increase students' motivation to speak in the classroom; for example, they can achieve this through the use of creative and amusing conversational activities. However, when it comes to increasing students' motivation to read in class, instructors normally consider this a more challenging task. This mixed-methods research examines the role of reading strategies as a tool to increase students' motivation to read in class in a business English course at the University of Costa Rica (UCR). To collect the data, the researcher made use of a pre-test, a post-test, two questionnaires, and an observation form. The results of the research show that $67 \%$ of the students claimed to feel more motivated to read in class after the teaching of reading strategies, as well as an increase of $58 \%$ in the approval rate in students' performance. From the data obtained, the researcher concludes that explicit strategy training helps students become more actively engaged when doing in-class reading activities and boosts students' confidence when tackling written texts.
\end{abstract}

Keywords: EFL, in-class reading, motivation, reading strategies.

\section{Introduction}

It is no secret that for many students in-class reading is a tedious activity, especially when the class is on a Saturday morning. That is why instructors must find ways in which in-class reading becomes engaging, fun, and purposeful. Regardless of the kind of motivation students have, either integrative or instrumental—as described by Saville-Troike (2005, p.86)— learners do not always see the purpose behind a reading lesson, losing their motivation and potentially increasing their affective filter, which would make input less likely to transform into intake, as explained by Krashen in Mitchell and Miles (2004, p. 48).One way in which instructors can help learners engage more with in-class reading is by using different strategies: cognitive, metacognitive, and socio-affective ones. Consequently, this research project aims to contribute to the understanding of the capacity to address the challenge of providing students with more engaging and purposeful in-class reading lessons, by addressing the question: 'Can the teaching of the strategies activating previous knowledge, predicting, skimming, and scanning improve students' motivation for in-class reading in an advanced business English class?' Additionally, the researcher will attempt to determine the strategy that learners used the most in class and the one they considered the least useful. In the same

1josefabian.elizondo@ucr.ac.cr; jelizondog@uned.ac.cr 
fashion, as the researcher is also the teacher in charge of implementing the strategies, he will gather first-hand information on the strategies that yielded the most positive results.

\section{Review of the literature}

\subsection{Learning Strategies}

When conducting research on the impact of teaching reading strategies on the L2 learning process, it is vital to analyze what has been written on this subject thoroughly. To start with, Saville-Troike sheds a light on this matter: "differential L2 outcomes may also be affected by individuals' learning strategies: i.e. the behaviors and techniques they adopt in their efforts to learn a second language" (2005, p. 91). As this author suggests, the learning of a second language exceeds the role of traditional teaching. Students' attitudes toward learning an L2 and the approaches they use to learn it have a determining role in the final outcome. For that reason, examining each of the three types of strategies involved in the process of learning will play an important role in this research. The Cognitive Academic Language Learning Approach (CALLA) is an instructional model developed by Anna Uhl Chamot and J. Michael O'Malley aimed to helping ESL students to be able to participate in a subject class for native speakers (Chamot \& O'Malley, 1987, p. 259). CALLA provides transitional instruction for upper elementary and secondary students at intermediate and advanced ESL levels. It is divided into three types of strategies (Chamot \& O'Malley, 1987, p. 264).

\subsubsection{Cognitive Strategies}

The first type of strategy deals with cognitive learning. It consists of L2 learning through the manipulation of cognitive strategies through rehearsal, organization, and elaboration (Chamot \& O'Malley, 1987, p. 259). In this category, the strategies relate to the way in which the students cognitively interact with the task to learn the language. Moreover, cognitive strategies can be used "to accomplish both content and language tasks" (Chamot \& O'Malley, 1987, p. 264). For the purposes of this research, four cognitive reading strategies will be analyzed: activating prior knowledge, predicting, skimming, and scanning.

Activating prior knowledge can be defined as using previous schemata to relate new to known information and making personal associations (Chamot \& O'Malley, 1987, p. 265). The importance of this strategy is clearly addressed by Neil Anderson in "Strategy One: Activate Prior Knowledge": "A significant amount of research has been conducted by second language reading researchers indicating that reading comprehension and reading skills are enhanced when prior knowledge is activated" (1999, p. 12). As suggested by Anderson (1999), the activation of background knowledge plays an effective role in the process of learning because it helps students make connections between the schemata they already have on the topic and the new information they are acquiring on the topic (p. 12). As a result, this strategy facilitates the retention of concepts. In other words, using this reading strategy can help students internalize new concepts because they can create mental connections between old and new concepts. Even more, not activating previous knowledge may result "in various degrees of non-comprehension" (Carrell, Devine, \& Eskey, 1988, p. 80).

Another reading strategy to consider is predicting, which is anticipating the text by making predictions about it (Chamot \& O'Malley, 1987, p. 266). The relevance of predicting as a strategy goes beyond L2 reading assimilation (Nuttall, 1982, p. 118). As a matter of fact, this technique is seen as an indicator of proficiency: "The ability to predict is both an aid to 
understanding and a sign of it [...] it is a principle of learning that new information is more easily assimilated if it can be fitted into an existing framework of ideas" (Nuttall, 1982, p. 118). In other words, making hypotheses about the reading before reading it has the potential to enhance the effectiveness of the $L 2$ learning. Furthermore, even if students' predictions are wrong, they will have still increased their disposition to receive the new schemata (Nuttall, 1982, p. 118).

The final reading strategies to analyze are skimming and scanning. As defined by Grellet (1981), "both skimming and scanning are specific reading techniques necessary for quick and efficient reading" (p. 19). These two reading strategies are considered to be time bound, as to effectively use them, readers must swiftly move their eyes through a page to find the information needed within minutes. On the one hand, skimming refers to a strategy in which overall comprehension —or gist—is required. Readers, for example, make use of this cognitive strategy when looking for the main idea of a text. Since comprehension of small details is not necessary in some contexts, readers spend very few minutes determining what the main idea of a text is without paying much attention to elements that may seem unimportant. On the other hand, scanning refers to something different. This cognitive strategy does not call for text comprehension, since "we simply let our eyes wander over the text until we find what we are looking for, whether it be a name, a date, or a less specific piece of information" (Grellet, 1981, p.19). Readers may use this strategy when trying to locate specific information in a written text; as an illustration, when looking for the due date of a project in an e-mail chain. As noted in the previous example, readers may ignore what the e-mails are about, since what matters is one specific detail.

\subsubsection{Metacognitive and Social Affective Strategies}

The second type of learning strategies deals with "metacognitive processes in which students reflect on and identify their own abilities and approaches to learning" (Chamot \& O'Malley, 1987, p. 259). In other words, these strategies have to do with the understanding of how to learn from a personal perspective. In addition, metacognitive strategies attempt to regulate language learning by planning and self-monitoring (Saville-Troike, 2005, p. 91). As a consequence, using metacognitive strategies such as self-monitoring helps students judge their own performance while learning (Chamot \& O'Malley, 1994, p. 62). In the same fashion, self-assessment strategies, which include checking back, keeping a learning log, and reflecting on what has been learned, help students identify which learning techniques work better for them (Chamot \& O'Malley, 1994, p. 62). Finally, social affective strategies have to do with the interaction of learners with others and their own emotions (Saville-Troike, 2005, p. 92). The relevance of this kind of strategy was suggested by Chamot in 1994: "Social affective strategies are particularly important in second language acquisition because language is so heavily involved in cooperation and asking questions for clarification" (p. 62). Hence, techniques such as asking questions for clarification and working with classmates can help students obtain clarification and feedback, which is vital for ESL learners (Chamot \& O'Malley, 1994, p. 63).

\subsection{Motivation}

Some researchers assert that learning strategies play a role in student motivation. For instance, using metacognitive strategies gives students the tools they need to become accountable for their own learning process (Chamot \& O'Malley, 1996, p. 263), increasing their 
motivation. In fact, as suggested by Bandura (as cited in O'Malley \& Chamot, 1996), motivation can be "described in terms of the value that learners place on a task, their expectations for success in performing the task, and the extent to which they attribute responsibility for learning to internal rather than external sources" (p. 263). That is, L2 learners' self-teaching is intrinsic to their motivation. Subsequently, there are two types of motivation that will be analyzed in this research. The most recognized types of motivation are integrative and instrumental (Saville-Troike, 2005, p. 86; Carrio-Pastro \& Mestre 2014, p. 241).

Firstly, integrative motivation "is based on interest in learning L2 because of a desire to learn about or associate with the people who use it (e.g. for romantic reasons), or because of an intention to participate or integrate in the L2-using speech community" (Saville-Troike, 2005, p. 86). In other words, this kind of motivation deals with an interest in interacting with the L2 speakers and their culture. The second type of motivation, instrumental motivation, "involves perception or purely practical value in learning the L2, such as increasing occupational or business opportunities, enhancing prestige and power, assessing scientific and technical information, or just passing a course in school" (Saville-Troike, 2005, p. 86). This type of motivation deals with personal goals that exclude L2 interaction. Finally, it is relevant to analyze the affective filter hypothesis. This hypothesis "captures the relationship between affective variables and the process of second language acquisition by posing that acquirers vary with respect to the strength or level of their affective filters" (Krashen as cited in Mitchell \& Miles, 2004, p. 48). In addition, "those whose attitudes are not optimal for a second language acquisition will [...] have a high or strong affective filter -even if they understood the message, the input will not reach that part of the brain responsible for language acquisition" (Krashen, 1982 as cited in Mitchell \& Miles, 2004, p. 31). Hence, this can be interpreted as a relevant learners' characteristic for both teachers and learners to take into account.

\section{Methodology}

\subsection{Context of the study}

Proyecto FR6012- Fortalecimiento del Ingles(English reinforcement project ${ }^{2}$ )is an educational project sponsored by CONARE ${ }^{3}$ and is being implemented in every public university in Costa Rica: ITCR, UNA, UNED, UTN, and UCR. In each university, the program has a different name, but their common goal is to provide public university students and staff members with English courses that would help improve the participants' level of English, using texts that would address tasks and language features relevant to students' fields of study. At UCR, this program has been called the "ESP" program, due to its seemingly similar approach to grouping learners based on their academic or occupational needs. Nonetheless, it is worth mentioning that this ESP program is a language program that does not conduct any needs analyses to determine potential learners' needs, wants, or lacks. Instead, the program categorizes learners based on their majors and places them in larger population groups: Social Sciences, Economic Sciences, Engineering, Medical Sciences, Agro-alimentary Sciences, Arts and Languages, and Staff Members.

\footnotetext{
${ }^{2}$ Our translation

${ }^{3}$ National Council of Public University Presidents (our translation).
} 


\subsection{Classroom Observation}

For this project, an Advanced II, Business English class was observed. This course was taught by the researcher once a week on Saturday mornings from 8 a.m. to 12 p.m. at the University of Costa Rica. This program uses the book Business Result Advanced for this level. The writers of the book series describe it as "a comprehensive multi-level course in business English suitable for a wide range of learners. The main emphasis is on enabling your students; helping them to communicate more effectively in their working lives" (Appleby and Grant, 2009, p.4). Both the ESP program and the writers of the book series share the same vision: helping students interact and communicate to make the learning meaningful. This philosophy is also shared by the teacher of this course. This researcher has been working in the field of TEFL for eight years and is about to finish his Master's in TEFL at UCR.

It is relevant to mention that there were twelve students enrolled in the course and they had been classmates for approximately two years. Additionally, the teacher of the course had been their instructor for about five months before the observations took place. To gather the data, the researcher observed three classes and used an observation instrument to conduct his focused observation.

\subsection{Pre-test and Post-test}

To compare students' use of strategies and motivation for in-class reading, the researcher applied a pre-test and a post-test. The pre-test was applied four weeks before the post-test. The learners were given a reading and a set of questions. These sets of questions were to be answered within a very strict time limit, and there were no explanations of reading strategies before the application of the pre-test. Neither the reading nor the results were discussed after the application of the pre-test.

It is important to mention that the strategy of guessing meaning from context had been being taught for several weeks before the pre-test by the researcher, which could influence the results of the pre-test. It is also worth mentioning that at least five-out of the 12 studentshad already taken the course LM-1030 Reading Comprehension Strategies I at UCR in the past. Hence, many of these students had already been trained to make use of reading strategies consciously when dealing with reading comprehension exercises. The researcher did not know this piece of information until the application of the post-task, when the researcher started to explain how to apply reading strategies and the learners started talking about their experiences when taking the course LM-1030.

For the post-test, the students were given the same reading they were given for the pre-test four weeks later. They were given the same questions and the same time to take the test. The only difference was the implementation of the teaching of activating previous knowledge, predicting, skimming, and scanning as reading strategies in each of the sections of the posttest.

\subsection{Student Questionnaires}

After the pre-test and the post-test, the students were given a short questionnaire on their use of strategies, their motivation for in-class reading, their degree of understanding of the 
text, and about what they and the teacher could have done to improve their understanding of the text.

\section{Results and Discussion}

For the first observation, the teacher did not teach any reading strategy. The students were told that that day they would start with an activity related to reading. The teacher gave the instructions for the pre-test and the students followed them. For the first part of the pre-test, the students were only given 2 minutes. When the time had ended, an alarm indicated that it was time to move on to the following section; however, students made the general comment that they needed more time to complete the exercise. They were to answer eight questions whose answers could be found in the text by using scanning. The teacher made the comment that for the purpose of the activity he could not give them more time. For the second section, the students had to answer three True and False questions, in which they had to justify the false statements. They were given three minutes to complete this part. By the end of the three minutes, most of the students also made some comments as to the lack of time to complete the task. Interestingly, for the third section, the students were to identify the function of each major segment in the reading by matching the function to the name of each section. For this part, two minutes were given to complete the item. Even though two minutes might sound as too little time to identify the function of the segments, four students ended this section in 40 seconds and asked if they could use that extra time to complete previous sections. To this, the researcher said "Yes," as a way to keep these students interested and engaged in the pre-test. Once the two minutes for this section ended, the teacher collected the pre-test and distributed a questionnaire to know how students felt after taking the pre-tests. The researcher then noticed that as the pre-test took place, many students started yawning and changed their body postures to more "slouchy" ones. It seemed that whatever motivation they had to come to class was gradually disappearing, as some students did not take interest in taking the challenge of figuring out how to complete the exercise under the time constraints, since they only looked at the reading for a long time without actually answering the questions.

During the second class observation, the researcher could not get to apply/observe any reading strategy in class as the students had some individual formal presentations on corporate social responsibility (CSR) programs. Even though there were only twelve students in the class and each of them was instructed to take 10 minutes to develop their topic, most of them took from 15 to 20 minutes to present their speeches. The teacher had a reading lesson plan ready for that day, but the students seemed to have been extremely engaged by the CSR program presentations. Consequently, the teacher decided to focus on student talk time, since this is the last course in the program for these students and most of them would still benefit from some feedback on their oral production.

Lastly, for the third observation, the teacher started the lesson with activities that made students activate their previous knowledge and use predicting before reading. The teacher made sure that students understood the importance of applying strategies consciously to become better readers. It was in this moment-as mentioned before-that some students started talking about how good or bad their experience with the course LM-1030 had been. There were mixed opinions on their perceptions of using reading strategies, but the teacher decided not to talk about the topic, as the lesson for the day was about implementing strategies while reading in class. The teacher decided to present the reading strategies as if no 
one had studied them in the past before (which was true for other students who had not taken the course LM-1030). Before asking students to complete the first part of the post-test, how to use scanning was explained to students very briefly. The teacher wrote a simple description on the board and provided examples for students to understand how to implement that strategy in their post-tests. Before the second part of the test, the students were taught how to use skimming. Finally, for the last segment students were told that they could use a text-attack skill to determine the function of a paragraph within a text. Students were given more written instructions on this section in the same post-test.

Overall, the students seemed to be more engaged this time when taking their post-test than when they took the pre-test. Nonetheless, there was one student who behaved even more aloof this time. It seemed that he disagreed with what he had to do and actually paid more attention to his phone conversations than to the task itself. The teacher did not make any comments about it, as this same student had previously mentioned in some other class that he disliked reading. Unexpectedly, when the class was over, this student came up to the teacher and said that the problem was not the activity and he apologized for doing poorly in the test. He said that the problem with reading strategies is that they encourage people to not know everything and that he could not handle that. He explicitly said that in his major complete understanding is a must and not knowing something results in failing at performing a task. He apologized for his inability to let go of his need to know and understand every little detail in a text.

For the purpose of this research study, this student is referred to as Student A. In Figure 1, only this student ranked his comfort level to explain what the reading was about with a lower score than 5 in both the pre and the post-test, where as three other students went from scores below five to an average of 7 for the post-test (in a scale from 1 to 10 , where 10 indicated very comfortable and 1 very uncomfortable). This information confirm student A's comments at the end of the class and explains the great gap among students' ratings. Consequently, on average, students' ratings went from an initial 6 to a final 8 in their degree of comfort, which seems to indicate that strategy training may help students improve their confidence when tackling reading texts.

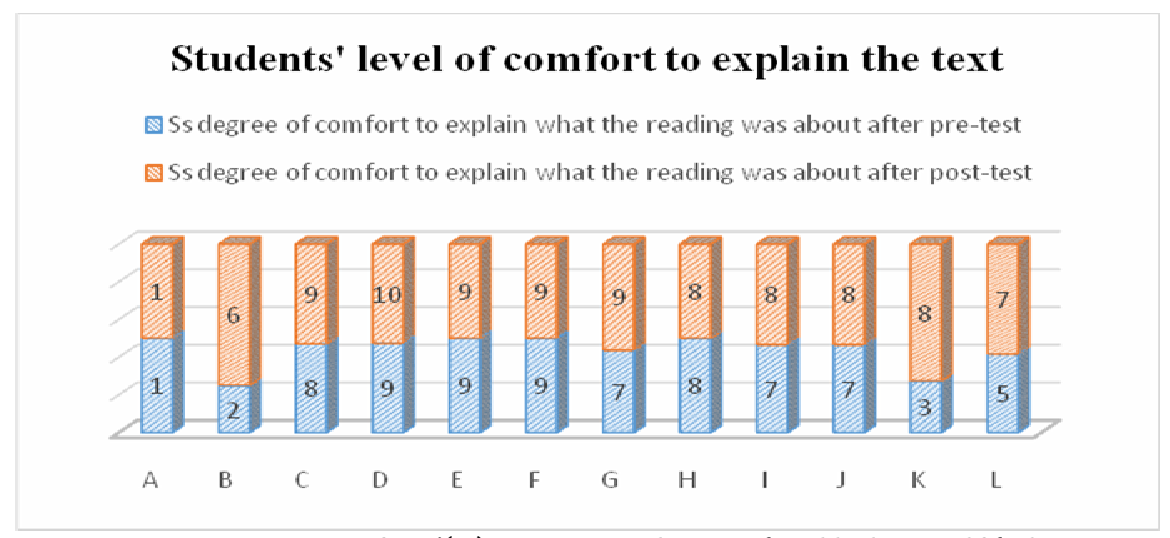

Figure 1. Students'(Ss) perception on how comfortable they would feel about explaining what the reading is about $\mathrm{N}=12$ 
As shown in Figure 2, only 16\% of students passed the pre-test (scoring more than a 70 ), whereas $75 \%$ of them passed the post-test. The researcher believes that this could be the result of several factors. First, he believes that choosing the same text for both the pre and post-test could have positively affected students' performance, as they had already had contact with the same text. Another factor that could explain this improvement is the explicit teaching of reading strategies. Students seemed to be more eager to tackle the task while taking the post-test and this could have impacted the results of the post-test.

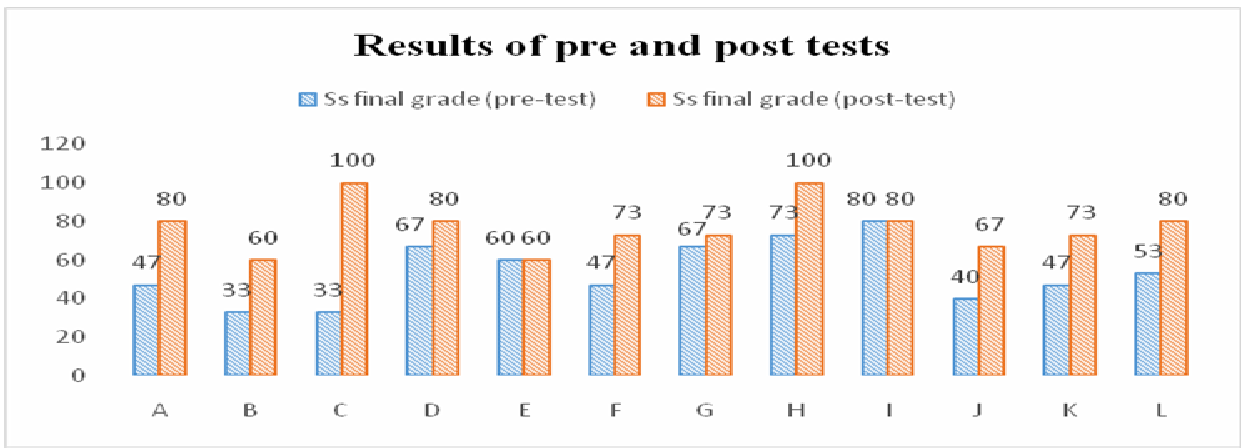

Figure 2. Final results of pre and post-tests $\mathrm{N}=12$

This specific argument, however, seems to be debunked by the analysis of students' answers related to their motivation to read in class after taking the pre and the post test. Students were asked to rank their motivation from 1 to 10 , ten being highly motivated. Figure 3 shows that students' motivation was not significantly altered or altered at all by the explicit teaching of reading strategies or the lack thereof.

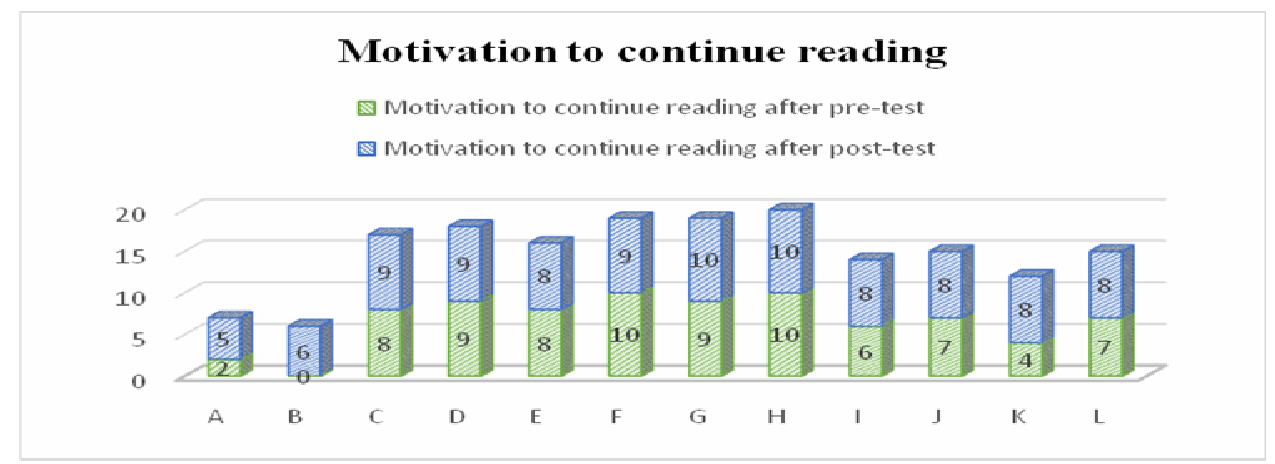

Figure 3. Motivation ratings after pre and post-tests $\mathrm{N}=12$

Out the 12 students, three of them expressed to be highly motivated after the pre test and these same three were also motivated after the post test, which may indicate that motivation does not correlate directly with the kind of activity presented to the students, but more with an instrumental or integrative motivation. In addition to these three highly motivated students, $42 \%$ of the students showed an increase in their motivation, ranking their motivation one or two points higher than before. Hence, even though there seems to be an increase in students' motivation, it seems to demonstrate that the explicit teaching of reading strategies does not play an important role in their motivation. 
Although some students did not consider that their motivation had improved a lot after using reading strategies for in-class reading, they did perceive that their performance had been better. In Figure 4, the researcher noticed that $75 \%$ of the students rated their performance as failingafter the pre-test, contrasting with their perception after the post-test, in which only $8 \%$ rated their performance as failing.

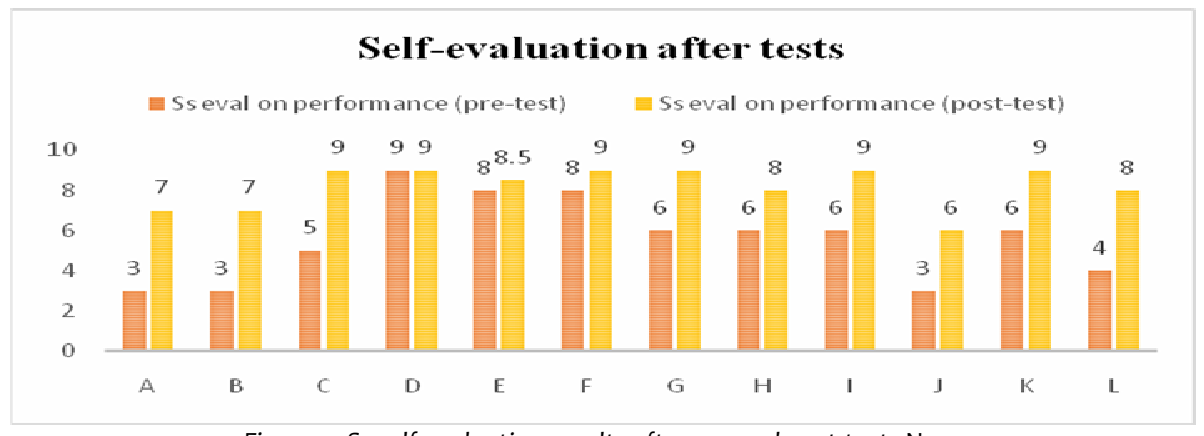

Figure 4. Ss self-evaluation results after pre and post-tests $\mathrm{N}=12$

These percentages are very similar to the results seen in Figure 1 for the pre-test, as $83 \%$ of the students actually failed the test. On the other hand, it was not $8 \%$ of the students who failed the post-test-as perceived by the students-but $25 \%$. The researcher believes that this discrepancy may be due to an issue of task completion. As explained before, when students took the pre-test, most them complained that they had not had enough time to complete each section fully; however, for the application of the post-test, many students seemed to have enough or extra time to answer the questions. Consequently, being able to complete the task under very specific time constraints may have had an effect on students' positive perception of their own performance.

Another factor that could have influenced students' actual performance and self-assessment rating could be their perception of their teacher's work. When asked what the teacher could have done to help students understand the text better, the following phrases stood out from the questionnaires:

1. More time or a general explanation about what we were going to read.

2. He could give better instructions.

3. Specifying the parts of the page that were relevant.

4. Give me more time to analyze it.

5. More time to catch [sic] all the text.

6. Avoid to tell us the time limit.

7. Give us a brief introduction of what the text was about.

8. Maybe if the teacher provides the "general ideas" or background to make the students feel interested on [sic] the topic.

9. Maybe before the test we could improve some tips to reading faster and look for better details.

Based on these comments, the researcher concluded that the students themselves believed that reading strategies could have improved their comprehension of the text. Comments 1, 7 , and 8 deal with activating previous knowledge; comments 4, 5, 6, and 9 deal with learning how to use skimming and scanning, and comment 9 deals explicitly with learning about 
reading strategies in general. Consequently, it is clear that students wanted the teacher to teach them reading strategies before the application of the pre-test.

To contrast these opinions, after the post-test, the students were asked again if there was something the teacher could have done to improve their comprehension of the text. These were some of the most salient comments:

1. The techniques or tips he give [sic] us helped me a lot.

2. Not really.

3. No, because now we have like a kind of "introduction."

4. No, he gives us the perfect tools to do it.

5. No, now I was better [sic] I think he did it right.

6. No, he already explain [sic] the strategies.

7. Well, I think the professor did his best effort to give clear instructions this time.

8. I think what he did was the most he could have done.

After reading this list, the researcher noticed how aware students were of the teaching of reading strategies in class and seemed to consider that what the teacher lacked during the implementation of the pre-test was improved for the implementation of the post-test. The researcher believes that his explicit teaching of reading strategies could have incidentally influenced students' actual and perceived performance when tackling the task, as they noticed that the instructor tried to give them the right tools to comprehend the text better.

To identify which strategy helped and which did not help students the most, students were asked to choose one from a list on the board: activating previous knowledge, predicting, scanning, and skimming. The most helpful strategy was scanning, since $50 \%$ of the students ranked it as the most useful reading strategy. As students were only asked to select one strategy from the list, the author was unable to support or further analyze students' choices. However, for the least helpful strategies, students were asked to describe why they considered the strategy they selected as the least helpful one. Contrary to what the researcher expected, 33\% of the students selected predicting as the least helpful strategy. Some of the arguments to choose this strategy as the least helpful one can be summarized in the following two explanations provided by some students:

1. "I don't like to talk about something I don't know."

2. "You can't really assume anything. It's better to take what the text says as the truth."

To analyze these results, the researcher also considered what Student A had said during the class observation and thought that it was a possibility that as many of these students are studying exact sciences, it can be difficult for them to see the value in something that asks them to relinquish control of what they do not know or understand, as predicting does.

\section{Conclusions and Recommendations}

Reading strategies help improve students' performance when doing in-class reading; however, this improvement does not seem to correlate with how motivated they are. As there was an increase of $58 \%$ approval rate in students' performance, the researcher expected a dramatic increase in students' motivation as well. Even though $67 \%$ of the students reported being more motivated after the post-test, their ratings varied in most of the cases from one to two ratings above-in a scale from one to ten-after being taught reading strategies explicitly. This means that students' motivation ratings went from a 7 to an 8 , which does not seem to indicate a dramatic change. Hence, this does not provide the researcher with 
information that could indicate that motivation is a determining factor for students' success. The results obtained seem to suggest that students who are taking majors related to exact sciences may seem to have a harder time understanding the concept of activating previous knowledge and predicting, as their opinions seem not to matter much when it comes to tackling a text, since they consider that the written text is the only source of input for them.

As recommendations for future projects, the researcher invites others to further investigate how students from different disciplines react to pre-reading activities that require students not to be exact and correct all of the time. Also, the researcher recommends conducting more studies over longer periods of time, as a way to be able to expose students to a wider variety of reading strategies, which in the end may consciously motivate them to use one or the other strategy for specific reading purposes. Finally, the researcher believes that the implementation of reading pre and post-tests should be an enjoyable activity for students to take and for teachers to implement, as this could become a factor that may influence how students perceive the teaching and learning of reading strategies.

\section{References}

Anderson, N.J. (1999). Exploring second language reading: Issues and strategies. Boston: Heinle \& Heinle Publishers.

Appleby, R. \& Grant, H. (2009). Business result: Advanced teacher's book. Oxford: Oxford Univ. Press.

Carrell, P. L., Devine, J., \& Eskey, D. E. (1988). Interactive approaches to second language reading. Cambridge: Cambridge University Press.

Carrio-Pastor, M. L. \& Mestre, E. M. (2014). Motivation in second language acquisition. Procedia - Social and Behavioral Sciences, 116, 240-244.

Chamot, A. U., \& Omalley, J. M. (1996). The Cognitive Academic Language Learning Approach: A model for linguistically diverse classrooms. The Elementary School Journal, 96 (3), 259-273.

Chamot, A. U., \& Omalley, J. M. (1994). The CALLA handbook: implementing the cognitive academic language learning approach. White Plains, NY: Pearson Education.

Chamot, A. U., \& Omalley, J. M. (1987). The Cognitive Academic Language Learning Approach: A Bridge to the Mainstream, TESOL Quarterly, 21(2), 227.

Grellet, F. (1981). Developing reading skills: a practical guide to reading comprehension exercises. Cambridge: Cambridge Univ. Press.

Mitchell, R. \& Miles, F. (2004). Second language learning theories (Second Edition). London: Arnold.

Nuttall, C. (1982). Teaching reading skills in a foreign language. London: Heinemann Educational.

Saville-Troike, M. (2005). Introducing second language acquisition. Cambridge: Cambridge University Press.

\section{Biographical notes:}

Jose Fabián Elizondo González is an EFL teacher who works both at Universidad de Costa Rica and Universidad Estatal a Distancia. He holds two master's degrees, one in Education Administration and a second master's in Teaching English as a Foreign Language. His 
graduation project involved the creation, implementation, and evaluation of an English course for Mechanical Engineering students. Hence, his research interests include language testing, language proficiency, and the teaching of culture. His work on such topics has been -and will be-- published in the journals Revista de Lenguas Modernas, Revista InterSedes, and Repertorio Americano. Finally, in 2017 Jose Fabián Elizondo became an ACTFL OPI certified tester. Consequently, he has been in charge of a language certification exam for the last three years. 